\title{
Effect of Mechanical Ventilation on Controlling Fire in Closed Room
}

\author{
May Salama \\ Computer Engineering dept. \\ Shoubra faculty of Engineering, Benha Univ. \\ Cairo, Egypt \\ e-mail: msalama@megacom-int.com
}

\author{
Magy Kandil, Samia Rashad \\ Regulation of Radiation \\ Nuclear Safety Authority \\ Cairo, Egypt \\ e-mail: Magy_kandil@yahoo.com
}

\begin{abstract}
The work models and simulates fire growth in a closed room. It examines the effect of various airflow rates of mechanical ventilation on wall and ceiling temperatures, Heat Release Rate, oxygen and carbon dioxide rates when smoke/fire is detected. The objective of the simulation is to find a way to control the temperature, fire growth and gas rates in the room until fire fighters have control of the situation. The model assumes that the ventilators are continuously operating. The results of the simulation show that there is a certain airflow rate for the mechanical ventilators that achieves the goal, thus avoiding fire breakout. The modeling and simulation is carried by CFAST which is a zone model tool for fire modeling and simulation.
\end{abstract}

Keywords- Closed Room, fire growth, CFAST, Mechanical Ventilation.

\section{INTRODUCTION}

A unit is protected against fire by detecting fire, preventing the spread of fire, mitigating it and suppressing it. In designing a mechanical exhaust system, make-up air should be provided to conserve mass. In general, make-up air should be supplied from positions below the smoke layer at lower velocity to give a flow rate that is less than the exhaust rate [1]. If make-up air positions are lying above the smoke layer interface, the mass of the smoke layer will be increased but the temperature will be significantly reduced due to mixing with much cooler air. As a result, the smoke layer will descend to lower levels. More ventilation would result in higher heat release rate and violent combustion. But less ventilation causes peaceful and stable combustion [2].

It is the required level of detail that specifies the fire model. Different models divide the building into different numbers of control volume [3]. The most common model is Zone model that uses two control volumes: upper layer and lower layer to describe a compartment. This approach is based on observation of such layering in real-scale fire experiments. Hot gases collect at the ceiling and fill the compartment from the top. While these experiments show some variation in conditions within the layer, these are small compared to the differences between the layers. Thus, the zone model can produce a fairly realistic simulation. On the other hand, field model divides the compartment into thousands of volumes. Accordingly, field models are able to predict the variation in conditions within the layers, but require much longer run times than zone models. Thus, they are used when highly detailed calculations are essential where the compartment is highly irregular. In zone models, it takes less time to simulate a fire and it is easily applicable on relatively small rectangular areas like cable spreading or pump rooms. The validation and verification of zone models are presented in [4].

It is required to protect a central room in a Nuclear Power Plant against catching fire or at least hindering fire break out in that room. The importance of that room lies in that the cables and devices inside it control other crucial devices. The work presented uses CFAST, which is a zone fire modeling tool.

The paper is arranged as follows: the description of the room and the fire model are presented in section 2. The mechanical ventilation is addressed in section 3. Simulation results are introduced in details and assessed in Section 4 showing the effect of different airflow rates on the fire growth and finally the summary in Section 5.

\section{FIRE MODELING OF THE ClOSED ROOM}

\section{A. General Description of the Room}

The room used in fire modeling in our work contains computer compartment, ductwork, and large structural beams. The top $2 \mathrm{~m}$ of the compartment is filled with cable trays containing cables, or ductwork, or large structural beams. The walls, floor, and ceiling are constructed from concrete of density $2240 \mathrm{~kg} / \mathrm{m} 3$, specific heat $1.2 \mathrm{~kJ} / \mathrm{kg} / \mathrm{K}$, thermal conductivity $1.4 \mathrm{~W} / \mathrm{m} / \mathrm{K}$ and thickness $0.5 \mathrm{~m}$. There are sixty cables in the room. The third and sixth cable trays above the fire source are filled with PE insulated, PVC jacketed control cables that are important to safe shutdown. The properties of the PE-insulated, PVC-jacketed (PE/PVC) cables are assumed to be as follows: density $1380 \mathrm{~kg} / \mathrm{m} 3$, specific heat $1.289 \mathrm{~kJ} / \mathrm{kg} / \mathrm{K}$, and thermal conductivity $0.192 \mathrm{~W} / \mathrm{m} / \mathrm{K}$ [5]. It is assumed that these thermoplastic cables fail when the temperature inside the outer jacket reaches $200^{\circ} \mathrm{C}$ [6]. These cables have a diameter of approx $1.5 \mathrm{~cm}$, a jacket thickness of approx $1.5 \mathrm{~mm}$, and $7 \mathrm{AWG} 12$ conductors.

The room has two doors on the east wall that are normally closed. Each door is $2 \mathrm{~m}$ wide by $2 \mathrm{~m}$ tall, with a $1 \mathrm{~cm}$ gap along the floor. There are two supply vents and two 
return vents, each with an area of $0.25 \mathrm{~m}^{2}$. The total air supply rate is $1.4 \mathrm{~m}^{3} / \mathrm{s}(3000 \mathrm{cfm})$. All vents are $2.4 \mathrm{~m}$ above the floor. Four mechanical vents are installed based on the geometry of the containment. It is assumed that the two doors are opened by an operator investigating a fire alarm. Smoke detectors are located on the ceiling. The detectors are UL-listed with a nominal sensitivity of $4.9 \% / \mathrm{m}$ as listed in [7]. Upon smoke detector activation, the mechanical ventilation fans start with suitable air flow rate.

As seen from the room description, it contains a lot of cables that control other critical devices. It is required to prevent or hinder those cables from catching fire in order to protect the attached devices. Controlling the room temperature is one way for deferring fire break until fire fighters are in control. This is the problem under investigation in this work.

\section{B. Fire Model}

A trash fire is assumed to burn within a cylindrical steel waste bin $0.8 \mathrm{~m}$ high and $0.6 \mathrm{~m}$ in diameter. The HRR of the transient fire is estimated using [8]. It is assumed that there is $5 \mathrm{~kg}$ of trash. The heat of combustion of the trash is assumed to be $20 \mathrm{~kJ} / \mathrm{g}$ based on an average for various items that could be encountered in a trash can. The fire is assumed to grow following a "t-squared" curve to a maximum value of $130 \mathrm{~kW}$ in $600 \mathrm{~s}$. The fire is assumed to burn at its maximum value until the trash is consumed. The radiative fraction of the fire is assumed to be $35 \%$, consistent with typical sooty fires. The soot yield of the fire is assumed to be $1.5 \%$, typical for wood and other cellulosic materials as mentioned in [6].

\section{MECHANICAL VENTILATION}

A simple model of ventilated compartment fires is developed in [9]. The model is based on a quasi-steady simplified energy equation with a simple wall heat loss model. The model is valid only for times up to 2000 seconds. The approximate compartment hot gas layer temperature increase, $\Delta \mathrm{T}_{\mathrm{g}}$, above ambient $\left(\mathrm{T}_{\mathrm{g}}-\mathrm{T}_{\mathrm{a}}\right)$ is given by the following equation:

$$
\Delta \mathrm{T}_{\mathrm{g}}=\mathrm{T}_{\mathrm{g}}-\mathrm{T}_{\mathrm{a}}=\frac{\dot{\mathrm{Q}}}{\dot{\mathrm{m}} \mathrm{c}_{\mathrm{p}}+\mathrm{h}_{\mathrm{h}} \Delta_{\mathrm{T}}}
$$

where:

$\Delta \mathrm{T}_{\mathrm{g}}=$ hot gas layer temperature rise above ambient $\left(\mathrm{T}_{\mathrm{g}}-\mathrm{T}_{\mathrm{a}}\right)$ (K)

$\mathrm{T}_{\mathrm{a}}=$ ambient air temperature $(\mathrm{K})$

$\hat{\mathrm{O}}=\mathrm{HRR}$ of the fire $(\mathrm{kW})$

$\mathrm{m}=$ compartment mass ventilation flow rate $\left(\mathrm{k}_{\mathrm{g}} / \mathrm{sec}\right)$

$\mathrm{c}_{\mathrm{p}}=$ specific heat of air $\left(\mathrm{kJ} / \mathrm{k}_{\mathrm{g}}-\mathrm{K}\right)$

$\mathrm{h}_{\mathrm{k}}=$ convective heat transfer coefficient $(\mathrm{kW} / \mathrm{m}-\mathrm{K})$

$\mathrm{A}_{\mathrm{T}}=$ total area of compartment enclosing surfaces $\left(\mathrm{m}^{2}\right)$

As shown in equation (1), hot gas layer temperature rise is dependent on the compartment mass ventilation flow rate $\left(\mathrm{k}_{\mathrm{g}} / \mathrm{sec}\right)$. Thus, if the airflow rate of mechanical ventilation is adapted, then the hot gas layer temperature could be minimized in order to prevent breaking out of fire. The mechanical ventilation is provided by a method of supply air and exhaust air. The amount of supply air shall be approximately equal to the amount of return and exhaust air.

\section{SimUlatiOn RESUlTS}

Fire simulation was done in 1800 s with airflow rates 0 $\mathrm{m}^{3} / \mathrm{s}$ to $10 \mathrm{~m}^{3} / \mathrm{s}$. The results of $1 \mathrm{~m}^{3} / \mathrm{s}, 3 \mathrm{~m}^{3} / \mathrm{s}$ and $5 \mathrm{~m}^{3} / \mathrm{s}$ are represented graphically. Sequence of the simulation is as follows: 1- Fire occurrence, 2- Smoke or fire detection, 3Alarm triggered 4-The two doors opened immediately, one after the other. Mechanical ventilation was on all the time, it was not switched off at any time but only the air flow rate changed.

Fire was detected at time $=280 \mathrm{~s}$, which is considered quite a long time exposing the room components to reach high temperatures that would result in hazard.

In each of the simulations, the following was measured: atemperatures of the upper, lower layers and ceiling, b- heat flux, c- the concentration of oxygen, $d$ - the concentration of carbon dioxide, e- number of re-ignitions/

The rate of the oxygen gas is important as it contributes to the probability of re-ignition. The rate of carbon dioxide is important because it could cause suffocation to whoever is inside or might step in to extinguish the fire. However, we will discuss only the temperatures of the upper, lower layers and ceiling together with the heat flux and re-ignitions.

\section{A. Simulation without mechanical ventilation $\left(0 \mathrm{~m}^{3} / \mathrm{s}\right)$}

The results are presented graphically in figures 1 to 4 . Figures 1 and 2 show that the temperature of the room kept increasing continuously which meant hazard occurrence. Figure 3 shows that the concentration of carbon dioxide is increasing with the increase of simulation time while the rate of oxygen first dropped as oxygen was consumed in the fire; then when the doors opened, it started to increase again.

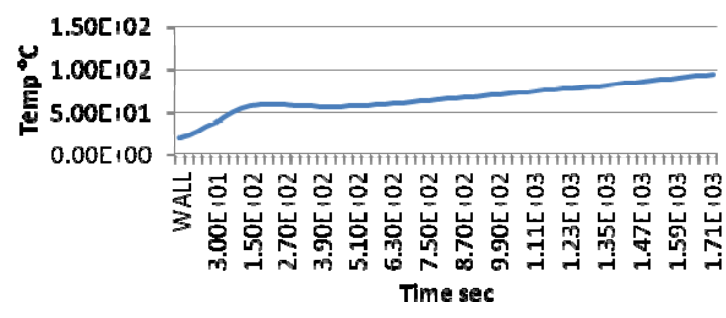

Figure 1. Temperature of Ceiling at no mechanical ventilation 


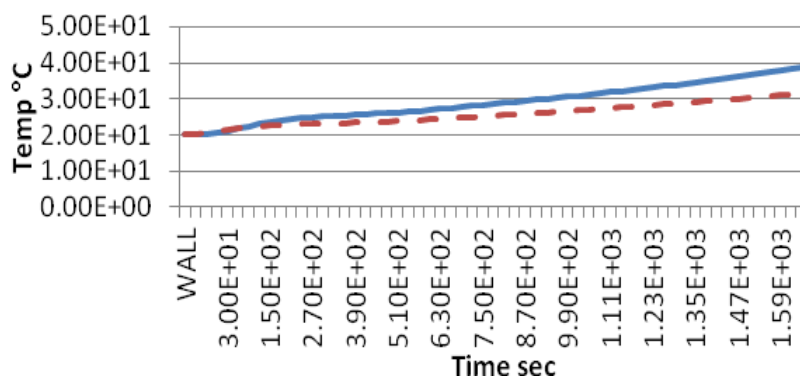

Figure 2. Temperature of upper and lower layers at no mechanical ventilation

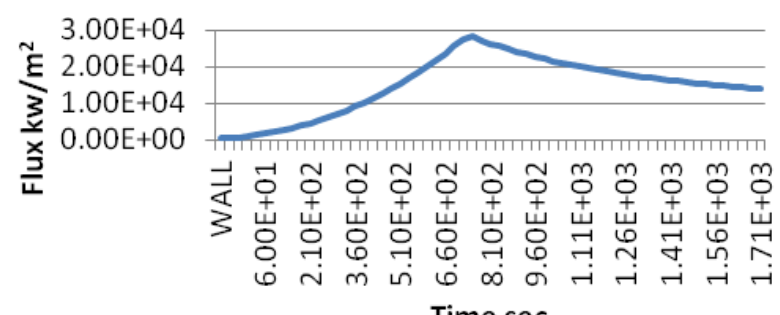

Time sec

Figure 3. Fire size at no mechanical ventilation

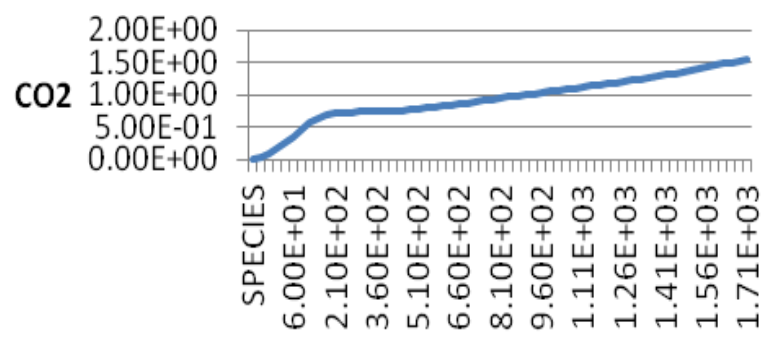

Time sec

Figure 4. Concentration of carbon dioxide without mechanical ventilation

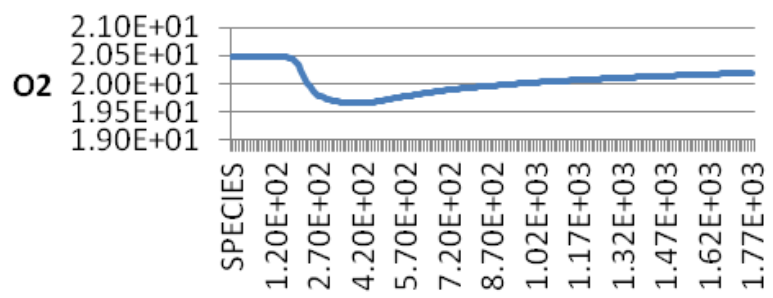

Time sec

Figure 5. Concentration of oxygen without the mechanical ventilation

\section{B. Mechanical ventilation with airflow rate $1 \mathrm{~m}^{3} / \mathrm{s}$}

The results at $1 \mathrm{~m}^{3} / \mathrm{s}$ are very similar to those of no mechanical ventilation.

\section{Mechanical ventilation with airflow rate $3 \mathrm{~m}^{3} / \mathrm{s}$}

The results are presented in figures 5-8. In figure 5, the ceiling temperature was almost constant at $20^{\circ} \mathrm{C}$ for the first 200 s from initial ignition. At 300s re-ignition occurred due to doors opening allowing more oxygen into the room and contributing for fire re-ignition. The temperatures of the upper and the lower layers in figure 6 show that temperatures started at $20^{\circ} \mathrm{C}$ and kept increasing. Just after doors opened, both temperatures decreased and kept decreasing, till the end of the simulation time. At $\mathrm{t}=1320 \mathrm{~s}$, temperatures were $23^{\circ} \mathrm{C}$ and $21^{\circ} \mathrm{C}$ for the upper and lower layers respectively. In figure 7 , the fire flux started from 0 at time 0 s (ignition) and increased to reach $800 \mathrm{w} / \mathrm{m}^{2}$, at reignition (time 300s) then started to decrease quickly to reach $420 \mathrm{w} / \mathrm{m}^{2}$ and continued to decrease to the end of the simulation time.

From the results, although there is one re-ignition occurring, the temperatures of the ceiling, upper and lower layers kept decreasing and tended to stay at a constant temperature. This means that the room components are being protected from overheating.

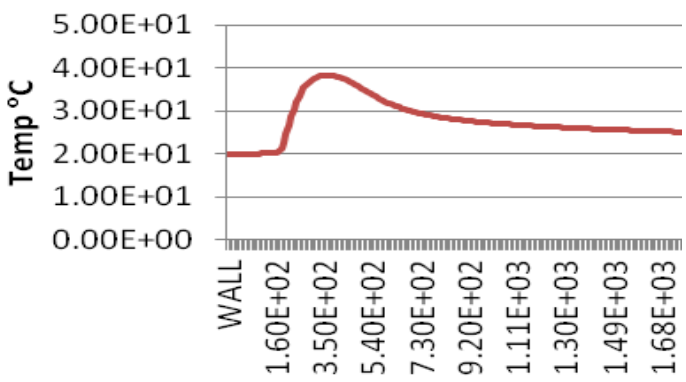

Time sec

Figure 6. Temperature of ceiling at flow rate $3 \mathrm{~m}^{3} / \mathrm{s}$ 


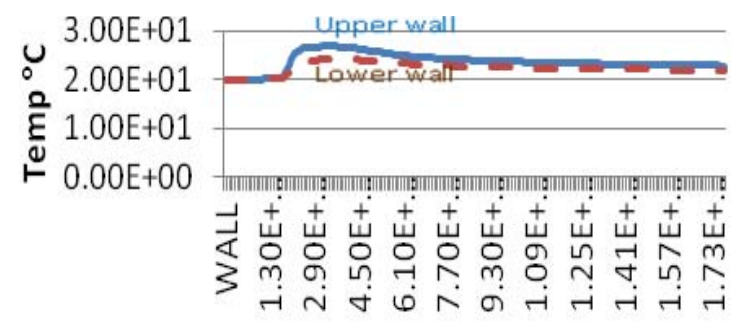

Time sec

Figure 7. Temperature of upper and lower layers at $3 \mathrm{~m}^{3} / \mathrm{s}$

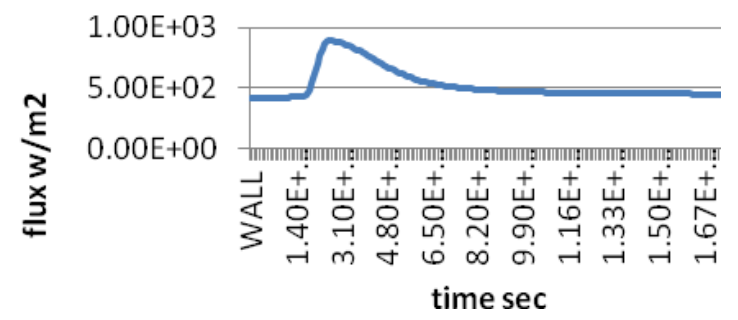

Figure 8. Fire size at flow rate $3 \mathrm{~m} 3 / \mathrm{s}$

Figure 9 represents the concentration of carbon dioxide as it increases till fire is detected; then a little drop occurs due to doors opening; then it drops by the end of the simulation time. This is a good sign for avoiding suffocation. In figure 10, the oxygen drops sharply in the beginning due to fire occurrence; then it maintains almost a constant rate.
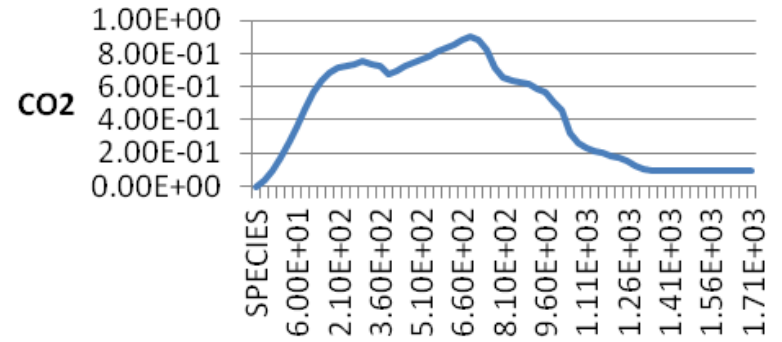

Time sec

Figure 9. Concentration of carbon dioxide with air flow rate $3 \mathrm{~m} / \mathrm{s}$

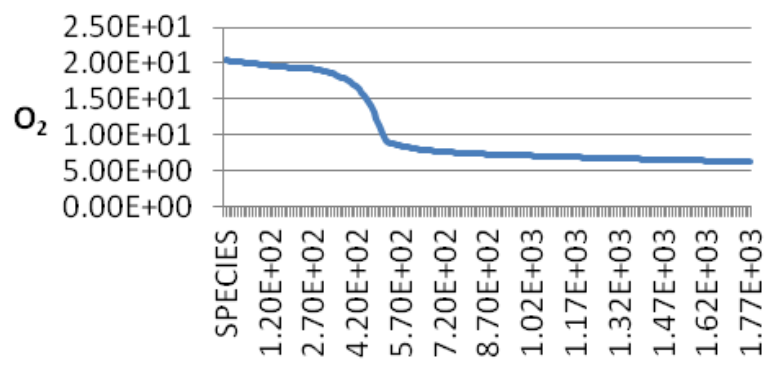

Time sec

Figure 10. Concentration of oxygen with air flow rate $3 \mathrm{~m} / \mathrm{s}$

\section{Mechanical ventilation with air flow rate $5 \mathrm{~m}^{3} / \mathrm{s}$}

The airflow rate is further increased since the results of $3 \mathrm{~m}^{3} / \mathrm{s}$ showed improvement over those of the $1 \mathrm{~m}^{3} / \mathrm{s}$. The results of $5 \mathrm{~m}^{3} / \mathrm{s}$ are presented in figures 11-14. As shown in figure 7 , the ceiling temperature increased till it reached $35^{\circ} \mathrm{C}$. When the doors opened, the temperature decreased to $20^{\circ} \mathrm{C}$. At time $=400 \mathrm{~s}$, re-ignition occurred due to air coming in. Temperature increased again to $70^{\circ} \mathrm{C}$ and stayed stable for a very short time. A second re-ignition occurred at time $=870 \mathrm{~s}$ and the temperature continued to increase till the end of the simulation time. The second re-ignition occurred due to the increase in the air supply allowing for much oxygen to enter the containment and contributing to a second reignition. Figure 8 shows that the temperature of upper layer started at $20^{\circ} \mathrm{C}$ and increased till it reached $40^{\circ} \mathrm{C}$. When the doors opened, the temperature decreased to $20^{\circ} \mathrm{C}$ then reignition occurred at $400 \mathrm{~s}$ and temperature increased to $100^{\circ} \mathrm{C}$; then re-ignition re-occurred at $870 \mathrm{~s}$ and temperature increased to $150^{\circ} \mathrm{C}$. The temperature continued to increase till $190^{\circ} \mathrm{C}$ at the end of the simulation time. The temperature of lower layer behaved similarly.

In figure 9 , the fire flux started from $400 \mathrm{w} / \mathrm{m}^{2}$ at time $0 \mathrm{~s}$ (ignition) and increased to reach $900 \mathrm{w} / \mathrm{m}^{2}$ at time 300 s then decreased to reach $600 \mathrm{w} / \mathrm{m}^{2}$, since the mechanical ventilation operated at time $=300 \mathrm{~s}$. Re-ignition occurred at 400 s and flux increased to $2000 \mathrm{w} / \mathrm{m}^{2}$. Then re-ignition reoccurred again at $660 \mathrm{~s}$ and flux increased to the end of the simulation time.

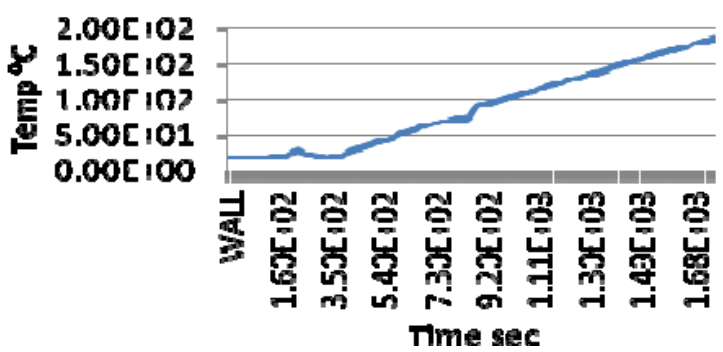

Figure 11. Temperature of ceiling at $5 \mathrm{~m}^{3} / \mathrm{s}$ 


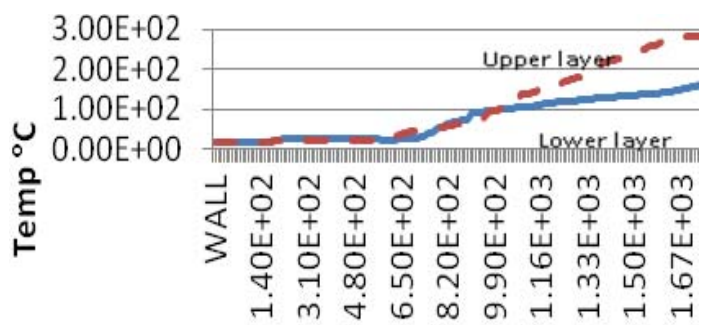

Time sec

Figure 12. Temperature of upper and lower layers at $5 \mathrm{~m}^{3} / \mathrm{s}$

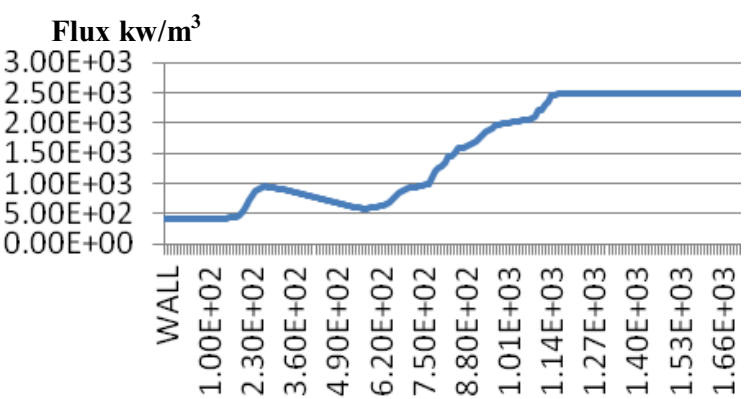

Time

Figure 13. Fire size at flow rate $5 \mathrm{~m}^{3} / \mathrm{s}$

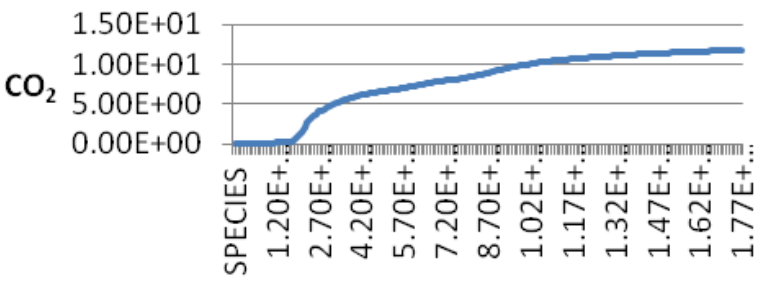

Time sec

Figure 14. Concentration of carbon dioxide with air flow rate $5 \mathrm{~m}^{3} / \mathrm{s}$

$2.10 \mathrm{E}+01$

$2.00 \mathrm{E}+01$

$\mathrm{O}_{2} 1.90 \mathrm{E}+01$

$1.80 \mathrm{E}+01$

$1.70 \mathrm{E}+01$

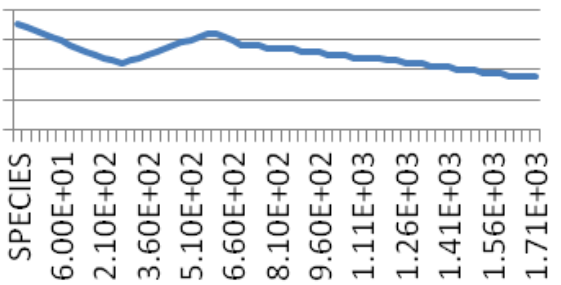

Time sec

Figure 15. Concentration of oxygen with air flow rate $5 \mathrm{~m}^{3} / \mathrm{s}$
From the results, it can be concluded that at airflow rate $5 \mathrm{~m}^{3} / \mathrm{s}$, two re-ignitions occurred while the temperature of the containment continued to increase; exposing the room to hazards.

Further simulations were done by increasing the airflow rate more than $5 \mathrm{~m}^{3} / \mathrm{s}$. The results of all these simulations showed an increase in room temperature and more reignitions. This led to carrying out more simulations with airflow rates in the range of $3 \mathrm{~m}^{3} / \mathrm{s}-5 \mathrm{~m}^{3} / \mathrm{s}$.

The best results were given at airflow rate $3 \mathrm{~m}^{3} / \mathrm{s}$.

\section{SUMMARY OF RESULTS}

The uncertainty of temperature predictions using CFAST, where the prediction is less than $500^{\circ} \mathrm{C}$, has been estimated as $-30 \%$ and $+40^{\circ} \mathrm{C}$. For predictions greater than $500^{\circ} \mathrm{C}$, the uncertainty is estimated to be $-30 \%$ and $+90^{\circ} \mathrm{C}$. Thus, temperature predictions should be adjusted appropriately to reflect the uncertainty of the predictions [10].

Table 1 summarizes the results. The simulation results were found to be coinciding with the results that have been reached by [11] that stated that the optimum air flow rate would be in the range of $2 \mathrm{~m}^{3} / \mathrm{s}-4 \mathrm{~m}^{3} / \mathrm{s}$.

TABLE I. RESULTS’ HIGHLIGHT

\begin{tabular}{|l|l|l|l|l|l|}
\hline $\begin{array}{l}\text { Flow } \\
\text { rate } \\
\mathbf{m}^{\mathbf{3}} / \mathbf{s}\end{array}$ & $\begin{array}{l}\text { Max/ } \\
\text { Min } \\
\text { ceiling } \\
\text { Temp. } \\
{ }^{\circ} \mathbf{C}\end{array}$ & $\begin{array}{l}\text { Max/ } \\
\text { Min } \\
\text { upper } \\
\text { layer } \\
\text { Temp. } \\
{ }^{\circ} \mathbf{C}\end{array}$ & $\begin{array}{l}\text { Max/ } \\
\text { Min } \\
\text { lower } \\
\text { layer } \\
\text { Temp } \\
{ }^{\circ} \mathbf{C}\end{array}$ & $\begin{array}{l}\text { Max/ } \\
\text { Min } \\
\text { Heat } \\
\text { Flux } \\
\mathbf{w} / \mathbf{m}^{2}\end{array}$ & $\begin{array}{l}\text { No of re- } \\
\text { ignitions }\end{array}$ \\
\hline 0 & $100 / 60$ & $40 / 25$ & $30 / 23$ & $\begin{array}{l}13500 / \\
10000\end{array}$ & 1 \\
\hline 1 & $100 / 60$ & $40 / 25$ & $30 / 23$ & $\begin{array}{l}13000 / \\
10000\end{array}$ & 1 \\
\hline 3 & $40 / 25$ & $25 / 22$ & $23 / 21$ & $\begin{array}{l}800 \\
420\end{array}$ & 1 \\
\hline 5 & $170 / 50$ & $190 / 25$ & $27 / 10$ & $\begin{array}{l}25000 / \\
600\end{array}$ & 3 \\
\hline
\end{tabular}

\section{CONCLUSION}

One of the most dangerous phenomena is re-ignition. The consumption of oxygen and the accumulation of un-burnt hot gases in the upper layer of a room may lead to this potentially dangerous situation when fresh air is suddenly introduced into the fire environment through vents such as doors. If a door is suddenly opened, fresh air will enter the room and lead to possible re-ignition and sometimes even a violent deflagration like re-ignition. Due to the lack of oxygen, the fire may have died out or may have gone through a stage of slow burning with smoldering combustion upon the arrival of the fire fighters. This situation is modeled for the optimum airflow rate of the mechanical ventilation and re-ignition time and frequency were exactly determined. Likewise, for any regular room, given its geometry and available ventilation, fire could be modeled and 
simulated to predict the best ventilation flow rate in order to control the temperature of the compartment in case of fire detection.

\section{REFERENCES}

[1] YUNG, D. and BECK, V. R., "Building Fire Safety Risk Analysis, Society of Fire Protection Engineers Handbook of Fire Protection Engineering", $2^{\text {nd }}$ Edition, National Fire Protection Association, pp. $5-95$ to $5-101,2006$

[2] Xiaojun Zhu, Chenhua Zhong, Zhiqing Yang, "Effects of Ventilation and Fire Power on Bulkhead Damage by Temperature Simulation Model and Experiment Analysis", Sixth International Conference on Internet Computing for Science and Engineering 2012

[3] Jones, W. "State of the Art in Zone Modeling of Fires", National Institute of Standards and Technology, 9th International Fire Protection Seminar, Munich May 25 and 26, 2001

[4] Lagdon, C. "CFAST Computer Code Application Guidance for Documented Safety Analysis", DOE-EH-4.2.1.4-Final CFAST Code Guidance, Final Report, July 2004.
[5] Gautier, B. "Fire Zone Model MAGIC Validation and Verification principles", International Collaborative Project to evaluate Fire Models for NPP applications May 2003, C 73- C 76.

[6] Najafi, B. "Fire PRA Methodology for Nuclear Power Facilities Volume 1: Summary \& Overview" Science Applications International Corporation (SAIC) EPRI 1008239 NUREG/CR-6850, Final Report, 2004

[7] "Cable Response to Live Fire (CAROLFIRE) Volume 1: Test Descriptions and Analysis of Circuit Response Data", NUREG/CR6931, Vol. 1, 2008

[8] Joglar, F. "Verification \& Validation of Selected Fire Models for Nuclear Power Plant Applications", Volume 4 Fire-Induced Vulnerability Evaluation (FIVE-Rev1), NUREG-1824 Final Report, NRC publications, May 2007 pp. 2.1-2.3

[9] Nowlen, S. "Heat and Mass Release for Some Transient Fuel Source Fires: A Test Report", NUREG/CR-4680, SAND86-0312, U.S.NRC, October 1986.

[10] Walton, W and Thomas. P. "SFPE Handbook of Fire Protection Engineering", chapter 6, 2008.

[11] McGrattan, K., Baum, H., Rehm, R., Hamins, A., Forney, G.P., Floyd, J.E. and Hostikka, S., "Fire Dynamics Simulator - Technical Reference Guide", National Institute of Standard and Technology, NISTIR 6783, Gaithersburg, Md. USA, 2001 